\title{
Features and Changes of Vowels of Eastern Yugur Language
}

\author{
Han $\mathrm{Wu}^{1, \mathrm{a}}$, Hongzhi $\mathrm{Yu}^{2, \mathrm{~b}}$
}

${ }^{1,2}$ Key Lab of China's National Linguistic Information Technology, Northwest University for
Nationalities, Lanzhou, Gansu 730000, China;

a1049507860@qq.com

Keywords: Eastern Yugur Language, vowel, reduction, diphthongization, devoicing.

\begin{abstract}
As one of the two native languages of Yugur nationality, Eastern Yugur Language has become an endangered language. The lack of a writing system makes harder the learning and protection of this language. Through the retrospect of the phonetic research, the article discusses the diachronic changes of this language trigger by both intrinsic and extrinsic elements in terms of vowel features. The article has clarified the phonemes and controversies concerning vowels in this language.
\end{abstract}

\section{Introduction}

As one of 56 officially recognized nationalities in China, Yugur Nationality has a small population of 14370 [1] and a long history. Yugur people can date back to Huihu people in Tang Dynasty. During its development, Yugur people had communicated and integrated with other ethnic people in neighboring areas. This has left striking influence upon its culture and languages. So far Yugur people speak two native ethnic languages --- Eastern and Western Yugur languages. The speakers of Eastern Yugur language is roughly one third of the population. Just like Western Yugur language, Eastern Yugur Language has also long lost its writing system; therefore, it is hard to get a glimpse into its original state. Though there were some sporadic documents about the ancestors of Yugur people, little is known about the phonetics of Eastern Yugur in history. The earliest records about Eastern Yugur speech had just been made in the 1880s, when G. N. Potanin [2], as the first westerner, stepped into the area inhabited by Yugur people. At the time of his exploration, Potanin noticed the peculiarities of these people --- sharing the same ethnic name "Yogur" (with different modifier "shira” and "xara”) and speaking two different languages ( "joyur Joz" and "Səra jogor lar", later are called Western Yugur Language and Eastern Yugur Language respectively). Following the steps of Potanin, many western explorers and scholars had been there and conducted some academic research on Yugur languages (mainly Western Yugur Language). Among these scholars of Eastern Yugur language, B. X. Todaeva [3] had participated the ethnic languages investigation program in 1950s undertaken by Chinese governments and had made a systematic study of Eastern Yugur language together with her Chinese colleagues. Based on linguistic materials collected, they hold that Eastern Yugur Language was just a dialect of Mongolian language, but later it was identified as an independent language of Mongolian languages.

Ever since 1880s, both western and Chinese scholars have carried on their study of Eastern Yugur Language, accumulated more and more linguistic materials and clarified many issues concerning this language. However, there are still many doubts and controversies in this very field, a retrospect into the development of Eastern Yugur Language will definitely enhance the understanding, and promote the protection and learning of this endangered language.

\section{Controversies Concerning Vowel Phonemes}

The understanding of Eastern Yugur Language is a gradual process and many controversies has occurred in it. The main controversy concerning Eastern Yugur Language is the number of vowel phonemes. As one of the pioneer scholars who has symmetrically described the phonology of this language, Todaeva holds that there are seven short vowels: /a, o, y, e, i, ö, ÿ/ (the Russian phonetic symbols /y, ö, $\ddot{y} /$ are actually IPA /u, ø, y/ respectively) and there are also five corresponding long 
vowels (short vowel /ö, $\ddot{y} /$ do not have long counterparts). In this vowel system, there isn't a schwa /ə/. Unlike the transcription by other scholars, the weak form of vowel is not indicated, for example, "taßen" (fifty) and "taaßen" (five) rather than the present transcription of "taßən" and "taaßən". Later Chinese scholars of Eastern Yugur Language have added some phonemes into this system. Junast [4] holds that there are eight short vowels (/i, y, e, ø, ə, a, u, o/) and seven long corresponding vowels (/i:, y:, e:, ø:, a:, u:, o:/). In contrast to Todaeva's vowel system, /ə/ is regarded as an independent phoneme. Bolčuluu et al $[5,6]$ holds that there are ten short vowels: /i, $\mathrm{y}$,

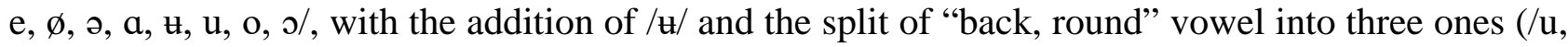
$\mathrm{o}, \mathrm{J} /$ ), and there are also seven corresponding long vowels (/i:, y:, u:, ø:, e:, ऽ:, a:/; $\quad \mathrm{u}:$ and /o:/ are rare cases). In 21st century, with the help of technology and facilities of experimental phonetics, scholars tend to agree that there are eight short vowels and seven long vowels in this language. Based on acoustic parameters, scholars tend to merge vowels $[\mho, 0,0]$ as one phoneme, but they used different IPA symbols for this phoneme: Sharengaowa [7] chose to use /o/ as the phonemic symbol, but Hashu [8] used / $\mathrm{s} /$ instead. Recently scholars of both Yugur languages have devised a unified vowel system to transcribe these two languages, and there are eight short vowels (/i, y, e, ø, $\partial, \mathrm{a}, \mathrm{u}, \mathrm{o} /$ ) and seven corresponding long vowels. So far a preliminary consensus has been reached in terms of vowel phonemes for Eastern Yugur Language.

Besides the controversies on the number of vowel phonemes, the phonetic values of some phonemes also vary greatly among scholars. Some of these controversies have shown the gradually improved understanding of this language. One noticeable case is the distinctive features of vowel "a”. Scholars used to think it was a "back, low and unrounded" vowel, but the acoustic parameters show that it is a "central" vowel rather than a "back" one, and the right IPA symbol should be / $/$ rather than [a] or [a]. However, some scholars are still using wrong phonemic symbols for the so-called convenience of writing. This results in another issue --- transcription norms of Eastern Yugur Language. It also causes inconvenience for the learner of this language.

Another controversy concerning vowels in Eastern Yugur Language is the distinctive features of so-called long vowels. Although the number of vowels varies in different phonological systems, the corresponding relationship between short and long vowels is universally acknowledged: except the schwa /ə/, all short vowels theoretically have long counterparts, and some long vowels such as / $\mathrm{u}:$ / and /o: / have quite low frequency in words. But the features of long vowel is not steady and are easily open to change due to the decreasing vitality of the language and language contact with other languages. Bolčuluu et al once listed 20 minimal pairs contrasting short and long vowels such as "xana” (where) --- "xanaa-" (to cough), "xan-" "to be satisfied” --- "xaan” (king, emperor), "xura” "rain"--- xuraa" (to fill in , to put into) etc. That has reflected the linguistic status of Eastern Yugur Language in 1980s. However, 20 years later Sharengaowa has pointed that these minimal pairs had reduced to 16 pairs. The four pairs which had lost their minimal contrast are: "xan-" "to be satisfied" --- “xaan” (king, emperor), “xwar” (printing plate) --- "xwa:r” (nose), “temen” (10 thousand) --"temeen” (camel), "tar” (weight unit) --- "taar”(hand-woven coarse cloth). The recent language survey shows that most speakers can only differentiate a very small number of these minimal pairs, and most likely rely on other means rather than the vowel duration to differentiate these words. Some of these words have already become homophones, for example, "temen" (ten thousand) "temeen" (camel). The gradual loss of vowel duration contrast in words reflected the decreasing vitality of Easter Yugur Language. For younger speakers (in comparative sense, most fluent speaker of Eastern Yugur Language are over 60 years old), their language competence has greatly weakened. The most apparent indication is that these speakers have already lost the ability to manage and differentiate some phonetic shades such as contrast of short and long vowels in some words.

\section{Phonetic Changes of Vowels}

Diachronically, vowels in Eastern Yugur Language have changed a lot and these have been thoroughly discussed: Bolčuluu et al have conducted a comparative study between Eastern Yugur Language and Mongolian (both modern and literary Mongolian). The vowels' corresponding 
relationship between Eastern Yugur Language and Mongolic had been analyzed in detail. They have already noticed some phonetic phenomena such as vowel reduction, elision in its development. Such comparative study has greatly enhanced the understanding of Eastern Yugur Language from a diachronic perspective. As for phonetic study, scholars of Eastern Yugur Language like to follow the research paradigm of Mongolian language, for example, the emphasis of the syllable position and structure: vowels are usually analyzed in different positions in a word (initial, mid and final syllable). This is due to the fact that the stress of Mongolian words usually falls on first syllable, and phonetic realization of a target vowel varies according to its position in a word. However, as a Mongolic language, Eastern Yugur language has been in close contact and under great influences of Western Yugur language (Turkic), the stress has shifted to the final syllable. This stress shift results in vowel reduction or elision in initial syllable: "basa" $\rightarrow$ "pəsa”(again, also), "bayan" $\rightarrow$ "bəyan" (rich), "bayar” $\rightarrow$ “bəyar (joy, happiness), “čagaan” $\rightarrow$ “ffagaan $/ \mathrm{f}$ Gaan”(white). Some reduction or elision also happens to vowels in mid syllables: "arakï” "arïkï” $\rightarrow$ "arəkə /arakə / arahgə (alcoholic beverage), "arasun” $\rightarrow$ “arəsən / arasən / arsən (skin; hide ), "abaga” $\rightarrow$ "abga / aßga” (paternal uncle). Without the help of a writing system, the transcription of words in Eastern Yugur Language solely depends on subjective perception, and the stress shift from the initial to the final has actually weakened the perception of vowels in unstressed syllable. This is why there are many transcription variations such as "noyan” (lord, chief) $\rightarrow$ "niyən”, "nyə:n” and “nion”.

Unlike the changes clearly shown in transcription forms, some phonetic changes are quite inexplicit and only exist in individual pronunciation of speakers. It is well known that some diphthongs have gradually evolved into single long vowels. In recent study we also find reverse evolution: in some cases, single vowels (/e/ or /e/) have developed into a diphthong ([ia] and [ie]). Although there are some diphthongs (/ ei, oi, əi/) in Easter Yugur language, diphthongs such as [ia] and [ie] are usually not regarded as the native phonemes of this language, and are only used to transcribe loan words from other languages (for example, Chinese), even though Junast [4] once transcribed two words this way: "tiag” (walking stick), "biar" (joy, happiness. As for [ia], other scholars like Bolčuluu [5] hold that this phonetic sequence is an indicator of palatalization of consonant and transcribed them respectively as "tjaag" and "bəjar". Therefore [ie] and [ie] are not independent phonemes, but just allophones of vowel /e/ and /e/ respectively. This is a phonetic phenomenon --- diphthongization. So far we have noticed that both /e/ and /e/ have diphthongized allophones, but the identification of the diphthongization of these two phonemes are quite different from each other: quite a few documents show that the diphthongization of /e/ has been recorded in Chines transliteration as early as in Yuan and Ming Dynasty. The following are examples of /e/ diphthongization recorded in Chinese and Ethnic Languages Dictionary (Huayi Yiyu): vowel " $\mathrm{e}$ " in the second syllable is pronounced as [ie] in the following words: "eme" (female), "ere" (male), "hure" (seed), "kelen" (tongue), "gedesən” (stomach, gut), "ede-"(to eat), etc. Compared with diphthongization of /e/, that of vowel $/ \mathfrak{e} /$ is a comparatively new phonetic phenomenon. It is becoming more and more prominent among speakers of Eastern Yugur Language. This very diphthongization shows speaker-relevant features and generational changes of Eastern Yugur Language. In our research , diphthongization of / $\mathrm{e} /$ becomes perceivable both physically and acoustically in words such as "dza gqăl-” (lightning), "Gadzaar" (land, earth, soil), "j̣gartfaG” (packsaddle), "qutfa-” (to bark), "artfa” (cypress) etc. As it is shown in Fig. 1, there are apparent differences between a diphthongized / $\mathfrak{e} /$ (in "art a") and un-diphthongized / $\mathfrak{e} /$ (in "bardam”). If / $/ \mathfrak{e} /$ is diphthongized, on the spectrum, Formant 1 and 2 of vowel $/ \mathfrak{e} /$ show striking features: at the very beginning of the very vowel, F1 goes down, F2 goes up, and there is an obviously perceivable transition. All the features are very like those of a diphthong /ie/. Besides the above-mentioned difference between diphthongization of $/ \mathrm{e} / \mathrm{and} / \mathrm{e} /$, the phonetic conditions of these two vowels are also different from each other: diphthongization of /e/ usually happens after consonants $/ \mathrm{t}^{\mathrm{h}}, \mathrm{t}, \mathrm{m}, \mathrm{l}, \mathrm{r}$, and is triggered by palatalized consonants; therefore it is the byproduct of palatalization and a phonetic changes driven by intrinsic linguistic elements. In contrast, the diphthongization of $/ \mathfrak{v} /$ usually takes place after consonants $\left[\mathfrak{t}\right.$, $\left.\mathfrak{y}^{\mathrm{h}}\right]$, but these two consonants are not the only phonetic condition for the diphthongization of $/ \mathfrak{r} /$, some $/ \mathfrak{e} / \mathrm{s}$ after these 
consonants will not be diphthongized, there is no diphthongization in the following words: "dzaluu"

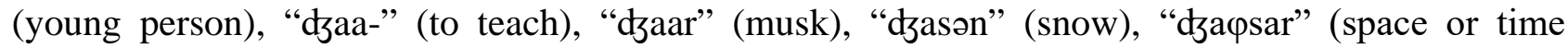
between, interval), "hdzan” (a load carried by a pack-animal ), "magaltyăG” (ankle), etc. Therefore, consonants $\left[\mathfrak{f}, \mathfrak{t}^{\mathrm{h}}\right]$ can only trigger diphthongization of $/ \mathfrak{v} /$, but they are not the determiners. Besides that, the frequency of diphthongization of $/ \mathfrak{e} /$ varies from speakers of different ages --- the younger speakers are more likely to diphthongize vowel $/ \mathfrak{e} /$. With careful study, we have found that the younger speakers tend to pronounce $\left[\mathfrak{t}, \mathfrak{t}^{\mathrm{h}}\right]$ in Eastern Yugur as $\left[\mathrm{t}, \mathrm{tc}^{\mathrm{h}}\right]$ in Chinese. In Chinese phonology, consonants $\left[\mathrm{t}, \mathrm{tc}^{\mathrm{h}}\right]$ do not go with vowel "a" (transcribed as [A]), and just go with "ia" (transcribed as [iA]). We try to sum up its rule as follows: diphthongization of $/ \mathrm{e} /$ is triggered by the transferred $\left[\mathfrak{t}, \mathfrak{t}^{\mathrm{h}}\right]$ (that is actually $\left[\mathrm{t}, \mathrm{tc}^{\mathrm{h}}\right]$ ). Therefore, the diphthongization of $/ \mathfrak{v} / \mathrm{is}$ triggered by extrinsic linguistic elements and is the direct influence of Chinese language upon Eastern Yugur language.

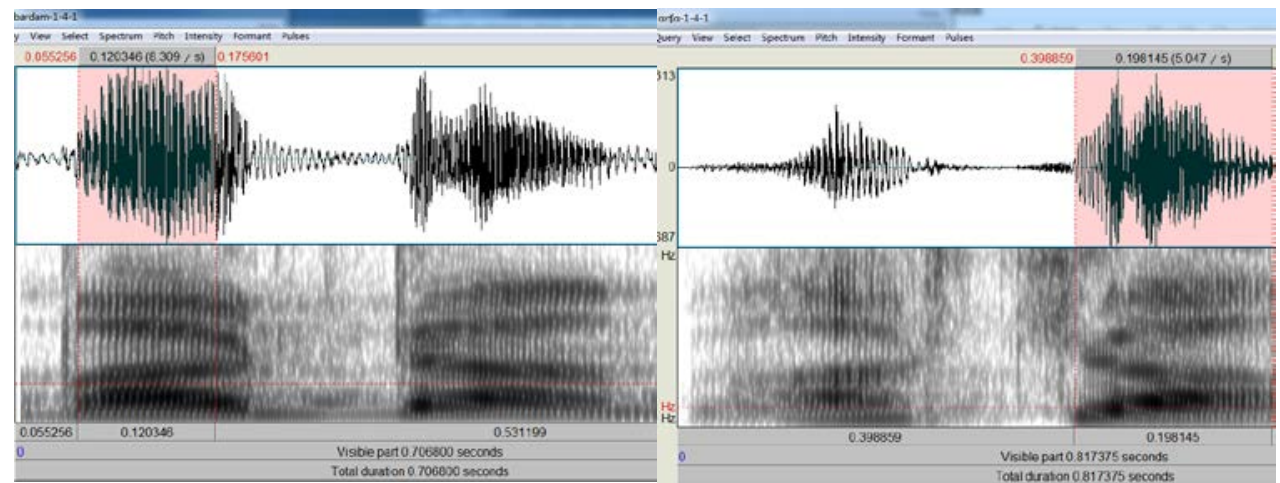

Fig. 1 un-diphthongized /ı/in "bardam” diphthongized /ı/in "artfa”

The third noticeable phonetic change is the devoicing of vowels in unstressed initial syllable, which is also caused by the stress shit from the initial to the final syllable. The devoicing in this language happens to several vowels: /i, u, o/ (selected parts in Fig. 2).

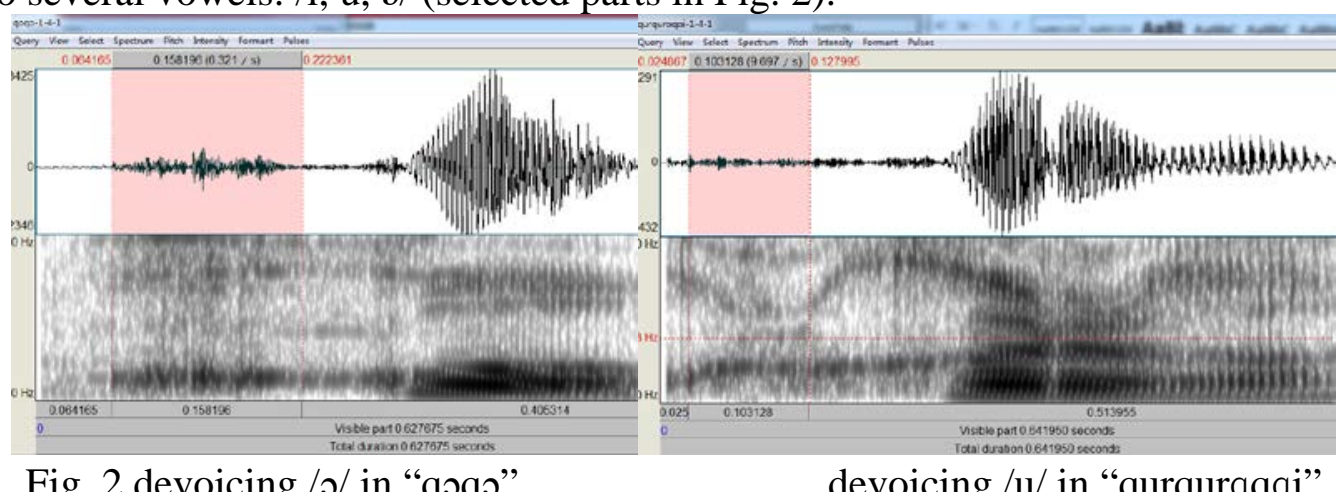

Fig. 2 devoicing / / / in “qэqo”,

devoicing /u/ in "qurquraqai"

If high vowels are further raised, the devoicing of these vowels occurs. This phonetic phenomenon is also observed in many other languages. However, this cannot explain all the devoicing phenomena, since vowel $/ \mathrm{J} /$ is not a high vowel. One possible explanation is that devoicing in Eastern Yugur also has something to do with proceeding consonants --- aspirated consonants (so-called strong consonants) and devoicing is a common result of the influence of these consonants upon the target vowels.

\section{Conclusion}

As the number of the native speakers is decreasing and at the same time being greatly influenced by other languages, Eastern Yugur Language has already been an endangered language. The fact that this language does not have a writing system helps worsen the situation. At present much attention has been paid to the protection of ethnic cultures and languages. The study of Eastern Yugur Language has only started 130 year ago; though some progress has been made, there is still long 
way to go so as to have a better understanding of this language. By probing into some features and changes of vowels in this language, we will see how this has changed in the past and how it will develop in the future. The key in this study is that we have classified the reasons of vowel changes: the ones triggered by intrinsic linguistic element and these are linguistic universals; the other changes are caused by extrinsic elements such as the influence from other languages via language contact. In a word, both academic probe into the language itself and a perspective of linguistic universals will definitely help the protection and learning of Eastern Yugur Language.

\section{Acknowledgement}

The work is financially supported by Open Project Program of Northwest University for Nationalities \& Project of Central Universities of NWUN: Multi-mode Phonetic Research (31920160002)

\section{References}

[1] Information on http://www.stats.gov.cn/tjsj/pcsj/

[2] Potanin, G. N. Chinese Tangut-Tibetan Area and Central Mongolia, St. Petersburg, 1893

[3] Tenishev, E. R. \& Todaeva, B. X, Yugur Languages, Moscow, 1976

[4] Junast, Concise Grammar of Eastern Yugur Language, Beijing, 1981

[5] Bolčuluu, et al. Vocabulary of Eastern Yugur], Hohhot, 1984

[6] Bolčuluu \& Jalsan, Eastern Yugur and Mongolian], Hohhot, 1990

[7] Sharengaowa, A Comparative Study between Mongolian and Yogour Phonetic System, Beijing University, 2008

[8] Hashu, Study of Eastern Yugur phonetics based on Acoustic Database, Inner Mongolian University, 2014 